\title{
Bodily modifications and the criminal law
}

Daniel Bansal ${ }^{*}$

\begin{abstract}
This article critically evaluates the law on bodily modifications and consent in English criminal law. The law on consent to (serious) bodily harm has been looked at on numerous occasions by both academics and the judiciary. The current position is that conduct must fall within one of four broad categories for consent to bodily harm to be effective - surgery, regulated sports, chastisement of children, and tattooing and ear-piercing. This article argues that extreme bodily modifications, which involves the infliction of grievous bodily harm, are not permitted when utilising the current category-based rationale favoured by the judiciary. This article posits that extreme bodily modifications are of such social disutility that their criminalisation must be correct. It is submitted that interference with personal autonomy is justified considering the significant inherent risks with such extreme procedures.
\end{abstract}

Keywords: Criminal law; bodily modifications; bodily harm; consent; theory.

\footnotetext{
* Daniel Bansal is a lecturer in law at the University of Leicester and doctoral researcher at the University of Birmingham. I am grateful to David Ormerod, Robert Cryer, and Milena Tripkovic for their very helpful comments on an earlier draft of this article. Email: daniel.bansal@le.ac.uk.
} 


\section{Introduction}

If $\mathrm{D}$ punches $\mathrm{V}$ as an act of bravado on V's part, the consent to the physical contact means that depending on the level of harm - no assault or battery takes place. If, however, D intends to exploit the opportunity to punch $\mathrm{V}$ and intends, or is reckless, to causing serious bodily harm by punching him as hard as he can, there is a point at which V's consent becomes irrelevant to the lawfulness of D's conduct. Following the seminal House of Lords decision in $R v$ Brown, ${ }^{1}$ it is only possible to consent to (serious) bodily harm if such conduct falls within one of the recognised exceptions and is of sufficient social utility. ${ }^{2}$ Beyond these exceptions the presence of consent is irrelevant in determining whether the infliction of bodily harm is lawful. Since this decision there has been extensive debate by legal scholars as to both the correctness of the decision and the proposed reform of consent to non-fatal offences. This issue is once again topical following a recent Court of Appeal decision in which certain 'bodily modifications' where held to be unlawful, despite the procedures being carried out on consenting adults. ${ }^{3}$ This article examines the emerging nature of 'bodily modifications' in society, the circumstances in which they are lawfully permitted, and whether extreme bodily modifications are justified. It is submitted that the answer to this question is where such modifications involve irreversible, life altering procedures that are not carried out by doctors - the answer must be never.

\section{Consenting to serious bodily harm}

The law concerning consent to non-fatal offences, specifically (serious) bodily harm, is an issue that has been looked at on numerous occasions. Non-fatal offences cover a wide ambit of

\footnotetext{
${ }^{1}$ [1993] UKHL 19; [1994] 1 AC 212.

2 The example above would not fit within the exceptions listed in $R v$ Brown (n 1). The 'social utility' model is looked at in more detail below.

${ }^{3} R v B M[2018]$ EWCA Crim 560.
} 
conduct from grievous life-threatening harm to minor battery and assaults. The offences are defined by two criteria; (1) the degree of harm suffered by the victim, and (2) the fault with which that degree of harm was caused by the defendant. For the purposes of this article, it is only the offences of grievous bodily harm ${ }^{4}$ and assault occasioning bodily harm ${ }^{5}$ that are considered. This article examines whether the physical integrity of the defendant is prioritised by the state, over consent to violation of said right, with respect to bodily modifications. ${ }^{6}$

The meaning of actual bodily harm ${ }^{7}$ in English criminal law has been interpreted as meaning any injury that interferes with the health and comfort of the victim that is more than transient or trifling. ${ }^{8}$ A wound is a caused when the whole of the skin, dermis and epidermis, has been broken. ${ }^{9}$ This includes the inner skin of the cheek, lip, or urethra. ${ }^{10}$ Determining whether or not the injuries are serious is not subject to an exhaustive set of criteria, however, relevant factors include significant medical intervention, and/or whether permanent effects have resulted. These criteria may be satisfied where there has been the need for stitches or a hospital procedure carried out under anaesthetic. ${ }^{11}$ Serious bodily harm ${ }^{12}$ covers both unlawful

\footnotetext{
${ }^{4}$ Contrary to the Offences Against the Person Act 1861 (OAPA), ss. 18 and 20.

${ }^{5}$ Contrary to the OAPA, s. 47.

${ }^{6}$ This dichotomy has been expressed by Sir William Blackstone, Commentaries on the Laws of England (3rd edn, Oxford: Clarendon Press 1768) at 120, "The law cannot draw the line between different degrees of violence, and therefore totally prohibits the first and lowest stage of it; every man's person being sacred, and no other having a right to meddle with it, in any the slightest manner."

${ }^{7}$ Contrary to the OAPA, s. 47.

${ }^{8} R v$ Miller [1954] 2 QB 282, at 292.

${ }^{9} R v$ Smith (1837) 8 C\&P 173.

${ }^{10} R v$ Waltham (1849) 3 Cox. 442.

11 For a more comprehensive account, see the CPS, 'Charging Standard' < https://www.cps.gov.uk/legal-guidance/offences-against-person-incorporating-charging-standard > accessed 7 April 2018. Assault occasioning actual bodily harm (ABH) may also include psychological harm that involves fear, distress or panic. See, $R v$ Chan-Fook (1994) 99 Cr. App. R. 147.

${ }^{12}$ Contrary to the OAPA, s. 20.
} 
wounding ${ }^{13}$ and the infliction of grievous bodily harm. ${ }^{14}$ Whether harm is grievous enough to constitute this offence is ultimately a question of fact for the jury. The CPS, in their charging standard, states that serious harm includes; permanent disability, significant visible disfigurement, broken limbs or skull, and serious psychiatric injury. ${ }^{15}$ The same level of harm is required for a s. 18 offence; however, the distinction is one of specific intent. It must be demonstrated that the defendant intended to inflict serious harm upon the victim. ${ }^{16}$ These harms are not trifling, but serious, and in some cases, life-changing injuries. Bodily modifications fall squarely within the ambit of a s. 18 offence since they are committed intentionally and result in significant visible disfigurement. ${ }^{17}$ Therefore, the question of whether an individual can consent to these harms is not only of theoretical significance, but practical importance, too.

Whether an individual can consent to (serious) bodily harm has examined by academics been on many occasions. ${ }^{18}$ There is debate amongst writers as to whether consent negates the element of the offence or is a defence to causing such harm. ${ }^{19}$ This theoretical question aside,

\footnotetext{
${ }^{13}$ Wounding means the breaking of the continuity of the whole of the outer skin, or the inner skin within the cheek or lip. It does not include the rupturing of internal blood vessels. Wounding may also include injuries that are relatively minor in nature, such as a small cut or laceration. However, for the purposes of a section 20 offence, wounds should be considered really serious.

${ }^{14}$ See, DPP v Smith [1961] AC 290; $R$ v Cunningham [1982] AC 566.

${ }^{15}$ CPS 'Charging Standard' (n 11).

${ }^{16}$ See, $R v$ Bryson [1985] Crim LR 669; $R$ v Brown (n 1); $R v$ Taylor [2009] EWCA 544.

${ }^{17}$ Some bodily modifications may result in permanent disability. This is the case where individuals are opting to have their ears removed, which may lead to the irreversible loss of hearing. See, $R v B M$ (n 3 ) [13].

${ }^{18}$ See, Julia Tolmie, 'Consent to harmful assaults: the case for moving away from category based decision making' (2012) 9 Criminal Law Review 656; Paul Roberts, 'The Philosophical Foundations of Consent in Criminal Law' (1997) 17(3) Oxford Journal of Legal Studies 389; and David Ormerod, 'Consent and Offences against the Person: Law Commission Consultation Paper no. 134 (1994) 57 Modern Law Review 928, 938-940.

${ }^{19}$ In sexual offences it is more sensible to adopt the former otherwise all acts of sexual intercourse satisfy the requirement of rape, contrary to the Sexual Offences Act 2003, s. 1, with consent providing a defence to such offence. It is not, however, within the ambit of this article to engage in such discussion.
} 
the judicial commentary on this subject provides valuable insight to this debate. There have been situations where the court have been prepared to accept consent as a defence to the infliction of harm. Such harm has included the tattooing of two boys aged 12 and $13,{ }^{20}$ minor operations performed by a suspended practitioner, ${ }^{21}$ the branding of the defendant's wife's buttocks with a hot knife, ${ }^{22}$ and injuries sustained through (reasonable) sporting conduct. ${ }^{23}$

The most important decision on this subject remains the House of Lords decision in $R v$ Brown. ${ }^{24}$ The house held that the defence of consent was not available to a charge of causing (serious) bodily harm when engaging in sadomasochistic acts. ${ }^{25}$ The decision was primarily based on the dicta of Lord Lane $\mathrm{CJ}^{26}$ that it is not in the public interest to permit people to cause each other actual bodily harm for no good reason. ${ }^{27}$ Therefore, to consent to bodily harm, conduct must fall within a recognised exception to be lawful. Lord Slynn summarised four broad categories whereby consent provides a defence to causing bodily harm as; (a) surgery, (b) regulated sports, (c) chastisement of children, ${ }^{28}$ and (d) tattooing and ear piercing. ${ }^{29}$ Categories (a) through (c) are all subject to a reasonable degree of force. Aside from the

\footnotetext{
${ }^{20}$ Burrell v Harmer [1967] Crim LR 169.

${ }^{21} R v$ Richardson [1998] 2 Cr App R 200.

${ }^{22} R v$ Wilson [1996] Crim LR 573.

${ }^{23} R v$ Barnes [2004] EWCA Crim 3246.

${ }^{24}$ (n 1). The facts of these are well known, and it is not necessary to go into detail here. Also see, $R v$ Meachen [2006] EWCA 2414.

${ }^{25}$ Contrary to the OAPA ss. 20 and 47.

${ }^{26}$ Attorney General's Reference (No. 6 of 1980) [1981] QB 715.

${ }^{27}$ The house also considered the decisions of $R v$ Coney (1882) 8 QBD 534; and $R v$ Donovan [1934] 2 KB 498.

${ }^{28}$ This is now governed by the Children Act 2004, s. 58. It is unlawful for a parent or carer to smack their child, expect where this amounts to 'reasonable punishment'. Whether a 'smack' amounts to reasonable punishment will depend on the circumstances of each case, taking into consideration factors like the age of the child and the nature of the smack.

${ }^{29}$ (n 1) 227. In addition, Lord Templeman at 231 held that ritual circumcision, tattooing, and ear piercing are all lawful activities. Lord Mustill, at 267, held that bravado and religious mortification are also harms that can be consented to.
} 
correctness of criminalising sadomasochistic activities between adults, the law on consent and causing bodily harm has been relatively well settled, even if unsatisfactory. Conduct must fall within one of the four categories to be lawful. ${ }^{30}$ This brings us to an interesting juncture. Individuals are more commonly choosing to express themselves in more daring and provoking ways than ever. ${ }^{31}$ People are, in addition to tattoos and piercings, wishing to express themselves by making 'modifications' to their bodies. The question is therefore - when is it permissible for an individual to make bodily modifications outside of cosmetic surgery? To elucidate this question, the recent Court of Appeal decision of $R v B M^{32}$ is evaluated in light of the jurisprudence on this subject.

\section{Bodily modifications}

Bodily modification, or body alteration, is the deliberate altering of the human anatomy or physical appearance for aesthetic purposes. This is commonly achieved with cosmetic surgery where individuals can pay to have facial contouring (rhinoplasty, chin or cheek enhancement), facial rejuvenation (facelifts, eyelid, neck and brow lifts), body contouring (liposuction), and breast augmentation. These surgeries are common in society and normatively accepted. More importantly, from the viewpoint of the criminal law, they are lawful. All of the above surgeries

\footnotetext{
${ }^{30}$ It is submitted that the current list of exceptions is both cursory and illogical. This category-based decision making has been criticised by Julia Tolmie, who suggests that it would be preferable to (a) permit reckless and intentional actual bodily harm where there is consent (b) permit grievous bodily harm unless there are public policy reasons that may force the removal of consent from the jury, which is ultimately a question for the judiciary based on the facts of the case, and (c) where death is intentional or subjectively risked, then no defence of consent would be available. See, Julia Tolmie (n 18). This is an approach that is based on the New Zealand Court of Appeal in Lee (2006) 22 C.R.N.Z. 568 (CA). It is submitted that this approach to consent and non-fatal offences still fails to remedy the uncertainty created by the 'patchwork' of categories listed in $R v$ Brown (n 1).

${ }^{31}$ The website 'Body Modification Ezine' currently has more than 3 million photos of people who've undergone various types of bodily modification. See, 'Body Modification Ezine' <www.bme.com> accessed 23 April 2018. Also see, Lois Bibbings and Peter Alldridge, 'Sexual Expression, Body Alteration, and the Defence of Consent' (1993) 20 Journal of Law and Society 356, at 361 32 (n 3).
} 
can be performed by a doctor in England and Wales. Under the Health and Social Care Act 2001, and guidelines issued by the General Medical Council, all cosmetic surgeons must be listed on a Specialist Registrar to perform these procedures. There is also a plethora of legislation that regulates the medical profession, the surgeries they can undertake, and the conditions in which they must take place. As such, they fall squarely within the recognised exception in Lord Sylnn's category-based rationale in $R v$ Brown. ${ }^{33}$ They are perceived across the world as being of both sufficient social utility and importance that they can be performed without medical necessity. At one end of the spectrum there are tribal and ritual bodily modifications that have been carried out for thousands of years - including male circumcision, ${ }^{34}$ lip and neck stretching, scarification, and teeth-sharpening. ${ }^{35}$ At the other end of the spectrum are cosmetic surgeries that are in abundance across the Western world. These types of procedures are not new and perceived as being either ritual or expressions/improvements of one's self.

One of the most common forms of bodily modifications are tattoos and piercings. They are seen by society as a form of expression, art, and a method of distinguishing one's self from others. They have long been carried out in England and Wales, with neither constituting a criminal offence when performed by a registered practitioner on a consenting individual. The

\footnotetext{
33 (n 1) 227.

${ }^{34}$ It is submitted that bodily modifications that are carried out for religious purposes, i.e. nontherapeutic, are supported by Article 9 of the ECHR, which guarantees respect for religious freedom, and authorise consent to such surgical operations. This is particularly relevant to the Jewish practice of circumcision for religious reasons. Such a view is also supported in David Ormerod and Karl Laird, Smith and Hogan's Criminal Law (14th edn, OUP 2015) 732. However, for an alternative position, see Howard Gilbert, 'Time to Reconsider the Lawfulness of Ritual Male Circumcision' [2007] EHRLR 279.

${ }^{35}$ The judiciary have been unwilling to accommodate these non-therapeutic foreign cultural practices. See, Adesanya (1974) The Times, 16 July. For a detailed analysis on this subject see, Sebastian Poulter, 'Foreign Customs and the English Criminal Law' (1975) 24 ICLQ 136. The disparity between lawful procedures and foreign practices, such as those listed above, further demonstrates the unprincipled justification on consent to bodily harm in the English criminal law.
} 
law currently permits these modifications, with bye laws that regulate the cleanliness and hygiene of said procedures. If they are carried out without the consent of the individual, however, they are subject to the offences of causing actual bodily harm. If the premises or procedures are not compliant with the local authority's requirements, they will also be subject to regulatory offences.

Other types of bodily modification, however, are more problematic and being performed more frequently. The term itself covers a wide variety of procedures, are unregulated, and require no qualification before they can be performed. Individuals are opting to have their ears reshaped to look pointed (Elvish), transdermal and subdermal implants placed under the surface of their skin to create patterns or anchors for jewellery, and corneal tattooing. The law makes no express mention of extreme body art in current legislation and are distinguished from regulated modifications such as tattooing and piercing. However, this has not deterred from people having such extreme procedures carried out.

This very issue has recently been deliberated by the Court of Appeal in $R v B M{ }^{36}$ The facts were distinct from any that the appellate courts appear to have examined before and offers useful insight into the types of bodily modifications that are permitted. The specific question for the Court was whether the defence of consent was available to an individual who caused serious bodily harm when performing bodily modifications to another. The case concerned an appellant who is, by trade, a tattooist and body piercer. He extended his services to include that of 'bodily modifications'. As part of these services, he performed several procedures including; (1) the removal of a customer's ear, (2) the removal of a customer's nipple, and (3) the

${ }^{36}$ (n 3). 
bifurcation of a customer's tongue to create something akin to a reptilian tongue. He was charged with three counts of wounding with intent to do grievous bodily harm. ${ }^{37}$ All of the customers either provided written consent for the procedures to be undertaken, or there was no evidence to suggest that the procedures were carried out against their wishes. It is important to note that the defendant was not a medically qualified professional conducting these procedures in sterile conditions with the proper equipment. All of these modifications were carried out without anaesthetic - albeit in a clean, tidy, and hygienic environment.

It is not currently possible in England and Wales to privately pay for these types of extreme bodily modifications to be carried out by a cosmetic surgeon. ${ }^{38}$ The evidence of both an ear, nose, and throat consultant, and a cosmetic surgeon, emphasised not only the inherent risks in performing each of these procedures but stated that they would not be performed by a cosmetic surgeon for aesthetic purposes, only legitimate medical reasons. ${ }^{39}$ Even where cosmetic surgeries are undertaken for medical purposes, several safeguards are put in place to protect the individual. The General Medical Council provides specific guidelines to cosmetic surgeons requiring them to refer patients that present potential psychological problems, especially Body Dysmorphic Disorder (BDD), which is symptomatic of the extreme demands of the customers in this case. A two-week cooling off period is also put in place to allow patients to change their mind and consider the long-term repercussions of such operations. ${ }^{40}$ All of the safeguards and procedures allows for the proper informed consent to be obtained by the patient. As the

\footnotetext{
${ }^{37}$ Contrary to the OAPA, s. 18.

${ }^{38}$ Whilst it is possible for a surgeon to carry out non-therapeutic plastic surgery, contraceptive surgery, and sex-change operations, the boundary between what is permitted where there is no therapeutic benefit is difficult to draw. See, Law Commission Consultation Paper No 139, Consent in the Criminal Law (1995) Part VIII.

${ }^{39}$ (n 3) [13].

${ }^{40}$ It is important to note that these surgical operations are only permitted when carried out by a medically trained surgeon in a hospital for the therapeutic benefit of treating BDD.
} 
defendant in this case was neither a medically qualified profession, nor performing the procedures for medical reasons, the safeguards were not available.

It is important to note that those who request such extreme bodily modifications may be suffering from BDD. It is a rare psychological condition that has a number of features. ${ }^{41}$ The main feature of the condition is a preoccupation with a defect in appearance. This may be, at one extreme, the imagination that one has too many limbs to the preoccupation with a minor defect such a spot or mark on the body. ${ }^{42}$ Its prevalence within society is not precisely known, however it is estimated to be around $1-2 \%$ of the general population, ${ }^{43}$ and up to $15 \%$ in the context of those who undergo cosmetic surgery. ${ }^{44}$ For those who suffer from BDD, reasonable surgical interference would be regarded as a forming an exception to general rule that bodily harm cannot be consented to. The precise limit of this exception is unknown as there is no specific ruling that sets out the parameters that surgical interference is such situations is lawful. ${ }^{45}$ However, if an individual suffered from BDD, a strict libertarian approach would protect an individual's claim to autonomy as overriding, recognising consent as a defence for reasonable surgical interference. ${ }^{46}$ However, the types of bodily modifications that we are concerned with here are (a) not being carried out by a doctor, and (b) not likely to be diagnosed with BDD. Therefore, the remainder of the discussion focuses on the situations outside of these circumstances. A more specific question is therefore - whether an individual, who is not

${ }^{41}$ The criteria required to satisfy the diagnosis of BDD is set out by the American Psychiatric Association, Diagnostic and Statistical Manual of Mental Disorders (4th edn, text revision Arlington, 2000) and also known as the DSM-IV-TR, at 507-510.

${ }^{42}$ See, Katharine Phillips, The Broken Mirror: Understanding and Treating Body Dysmorphic Disorder (OUP 1986) 33, and Katharine Phillips, 'Clinical Features and Treatment of Body Dysmorphic Disorder' (2005) III Focus 179, at 180.

${ }^{43}$ Katharine Phillips, The Broken Mirror (n 42) 21.

${ }^{44}$ DSM-IV-TR (n 41) 509.

${ }^{45}$ Margaret Brazier and Emma Cave, Medicine, Patients and the Law (4th edn, Penguin 2007) 100.

${ }^{46}$ Attorney General's Reference (No. 6 of 1980) (n 26). 
medically qualified, can perform extreme bodily modifications on an individual who has the capacity to consent? ${ }^{47}$

It is clear and unambiguous that bodily modification does not fit within the recognised exceptions above. The closest, (a) surgery, is not applicable since the appellant is neither a medically qualified practitioner, nor is the procedure carried out for medical purposes - both of which are essential. The question is therefore whether an entirely new recognised exception be created to accommodate the trending extreme bodily modifications. Lord Burnett of Maldon held that this question should be answered in the negative for several reasons. ${ }^{48}$ First, the criminal law performs a paternalistic role in limiting the approbation of the law for significant violence, irrespective of consent. Second, there is an inherent risk of unwanted injury when performing these types of procedures that will ultimately have a negative impact on society. Third, there is no discernible societal benefit in permitting such conduct. Fourth, if such conduct is to be permitted, and exception granted, it would be for Parliament, not the judiciary, to determine in a political environment. Such a decision is inherently concerned with making a normative assessment that is laden with policy considerations, of which there are likely to be conflicting views in society. Finally, significant importance was placed on the protection of public, which extends beyond the risk of infection, inadequate surgery, and an inability to deal with complications. The Court held that those who seek extreme bodily modifications, as in this case, invite an individual to perform irreversible surgery without anaesthetic with longterm consequences. Since it would be a reflexive response to advocate medical attention to those who seek to harm themselves in ordinary life, the same should be proposed here. It is

\footnotetext{
${ }^{47}$ For an excellent discussion on BDD and consent to surgical intervention, see Tracey Elliott, 'Body Dysmorphic Disorder, Radical Surgery and the Limits of Consent' (2009) 17 Medical Law Review 149. ${ }^{48}$ (n 3). The Lord Chief Justice held that consent was no defence in such circumstances and thus reaffirming the ratio in $R v$ Brown (n 1).
} 
imperative to ensure that individuals are not vulnerable or suffering from mental health issues, such as BDD, when requesting such extreme surgeries. Of course, it is not suggested that everyone who wishes to undergo such procedures fall within these categories, but some will be. Neither Lord Mustill's dissenting voice of reason in $R v$ Brown,${ }^{49}$ or the Law Commission, ${ }^{50}$ would have gone so far to suggest that the English criminal law should allow for consent as a defence to causing serious bodily harm in such circumstances. The reasons advanced demonstrate an unwillingness to permit serious bodily harm to be inflicted without good reason and placed in a special category of exception.

The decision, taking into account the various comments above, ultimately involved the balancing of a number of competing views that must be weighed up to determine whether bodily modifications are lawful. The onus is to demonstrate that these modifications constitute such an important social utility (with reasonable safeguards) that such conduct should be permitted. The Court of Appeal held that this threshold had not been met. The decision has the effect of stating that bodily modifications are of such little social utility, with high risk of further unintended harm, which should not be permitted even when conducted with the full consent of the customer. Once more the judiciary has chosen to favour the protection of the public and adopt a paternalistic role rather than recognising the individual autonomy of those wishing to pursue such procedures. Such a decision must be correct for the reasons outlined above. It is only when these modifications are perceived as being of sufficient social utility and normatively acceptable that this position may change.

\section{Philosophical justifications}

\footnotetext{
${ }^{49}$ (n 1 ).

${ }^{50}$ Law Commission, Consent in the Criminal Law (n 38).
} 
The criminal law tries to ensure that the principles of both physical integrity and privacy are protected. It argues for liberty from interference in ordinary-life, and those who interfere with such rights will be subjected to the repercussions of the criminal law. However, such principles are not universal and unequivocal. Just as an individual may consent to someone destroying or damaging one's property, ${ }^{51}$ individual autonomy may be used to argue for liberty to do with one's body as one wishes. Individuals may use this to consent to the infliction of (serious) physical bodily harm onto themselves. ${ }^{52}$ This is an important consideration in determining whether to permit bodily modifications since freedom of choice is a core social value within the libertarian framework that underpins the current structure of English criminal law. With this in mind, there is an important theoretical question - should the infliction of harm on a willing recipient, vetoing their physical integrity, be criminalised?

Whilst individuals in society do have a right to set their own boundaries of their bodily integrity and the types of conduct that they wish to be subjected to, the criminal law has chosen to set parameters on this for several reasons - the concern for the individual and collective welfare that is caused by such activities; the level of critical harm that is risked or intended by the defendants; ${ }^{53}$ the unpredictable nature of any possible harm; ${ }^{54}$ the difficulty in implementing safety mechanisms to prevent the occurrence of unintended harm: ${ }^{55}$ the potential for harm to escalate; and finally the adverse effect such conduct has on the public. ${ }^{56}$ These considerations place the protection of integrity of the individual over their autonomy to waive such right.

\footnotetext{
${ }^{51}$ Criminal Damage Act 1971.

52 This is apparent in everyday life, where sexual intercourse between two consenting adults, which requires the consensual infliction of harm, is permitted, in comparison to non-consensual intercourse in rape.

${ }^{53} R v$ Coney (n 27).

${ }^{54} R v$ Brown (n 1$)$.

${ }^{55} R v$ Brown (n 1) (Lord Jauncey of Tullichettle).

${ }^{56} R v$ Coney (n 27) and $R v$ Brown (n 1) (Lord Templeman).
} 
In balancing the conflicting values of personal autonomy and paternalism the judiciary has maintained a restrictive approach - conceding that it is only possible to consent to bodily harm (outside of the recognised categories) when there is a 'good reason' and it is in the 'public interest' to do so. This categorisation of harm fails to explain why some conduct is permitted and others prohibited, evident from just a peripheral glance at the judicial dicta. For example, it is not clear why horseplay resulting in bodily harm is permitted when sadomasochistic activity is not. Andrew Ashworth has commented that this may be due to the judicial disgust at those who engage is sadomasochism compared with the view that the armed forces (in the case concerning horseplay) ${ }^{57}$ consist of decent people. ${ }^{58}$ This shows that the reasons offered are unprincipled and do not explain the circumstances in which liberty can be vetoed. For example, there are no satisfactory reasons why lawfully organised sports, such as boxing, are able to waive liberty and be subjected to very serious and life-altering injury. On this point, in Pallante $v$ Stadiums Ltd., ${ }^{59}$ McIneary J tried to reach an intellectually satisfying account of the apparent immunity of professional boxing from the demands of the criminal law, but ultimately concluded that such an endeavour is futile. ${ }^{60}$

It is submitted that the philosophical justification of paternalism is often advanced as a façade for legal moralism. Legal moralism asserts that it is morally permissible for the criminal law, and society, to enforce moral standards irrespective of whether the prohibited conduct would result in harm to others. It is submitted that there is greater evidence of legal moralism being used to justify interference than paternalism in the judicial dicta concerning consent to bodily

\footnotetext{
${ }^{57} R v$ Aitken [1992] 1 WLR 1066.

${ }^{58}$ See, Jeremey Horder, Ashworth's Principles of Criminal Law (8th edn, OUP 2016) 312.

${ }^{59}$ [1976] VR 311.

${ }^{60}$ See, (n 3) [38].
} 
harm. In $R v$ Donovan, ${ }^{61}$ the court described the infliction of bodily harm for sexual gratification as being 'revolting', 'perverted', and the result of a 'corrupt motive'. ${ }^{62}$ Similarly, in $R v$ Brown, ${ }^{63}$ the court stated that their function was to mark disapproval of the activities that were carried out by the defendants. The judiciary in both cases have clearly adopted a Devlinian $^{64}$ view that society and the law is entitled to protect themselves from danger and immorality without any (theoretical) limit. The combination of paternalism and legal moralism means that the criminal law is entitled to interfere with individual autonomy when bodily harm reaches a critical level because, if left unchecked, the consequences would be unacceptable. Such provision places the preservation of the participant's future physical well-being over their autonomy to consensually engage in harmful conduct. Such philosophical justifications are clearly of relevance to bodily modifications and the criminal law.

In addressing the question of bodily modification and consent, there is undoubtedly the relevance of human rights. A rights-based approach is often invoked when personal autonomy fails to provide a satisfactory outcome. Article 8.1 of the ECHR demands the respect the one's private life and is of significance to the criminalisation of the consensual harm discussed here. In Laskey $v U K,{ }^{65}$ the European Court of Human Rights held that the criminal law's interference is justified as being 'necessary in a democratic society' for 'the safeguarding of public health'. The Court focused, not just on the sadomasochistic conduct, but the significance of the degree of injury or wounding. The question, with this Strasbourg jurisprudence in mind,

\footnotetext{
${ }^{61}$ (n 27).

${ }^{62}$ (n 27) 509.

${ }^{63}$ (n 1 ).

${ }^{64}$ Patrick Devlin, The Enforcement of Morals (OUP: London 1965) 12-13.

${ }^{65}$ (1997) 24 EHRR 39. For an illuminating discussion on this topic, see Leslie Moran, 'Laskey v The United Kingdom: Learning the Limits of Privacy (1998) 61 Modern Law Review 77.
} 
is whether the consensual harm, in so far as they are expressions of autonomy, goes too far and there is a significant risk of serious injury involved.

The applicability of this to extreme bodily modifications highlights the uncertainty of categorybased decision making offered in $R v$ Brown. ${ }^{66}$ It is submitted that both the judiciary and Parliament ought give greater attention to the principle of personal autonomy - requiring the recognition that in some circumstances, an individual may wish to protect their negative right to personal autonomy, and their right to engage consensually with others and subjected to bodily harm. This is not the approach that has been adopted by the courts, though - instead opting for a paternalistic (or moralistic) approach. It is clear that the value of free will and personal autonomy is not weighted as highly when applied to a philosophical framework that is built upon paternalism and moralism. ${ }^{67}$

Moving forward, it is submitted that the law's treatment of the consent of a sane adult to bodily modifications is likely to go down one of two routes - (1) the continued criminalisation of consensual bodily harm will be evaluated on a case by case basis by the judiciary using category-based rationale. This has the effect of producing uncertainty in the criminal law with respect to extreme bodily modifications, and other acts like sadomasochism, driving them underground and performed in undesirable circumstances; or (2) Parliament over-hauling nonfatal offences and the availability of consent to the kind of conduct discussed here. Considering the detailed proposals by the Law Commission and fierce academic commentary, it appears that the first of these two options is likely to continue for the foreseeable future.

\footnotetext{
${ }^{66}$ (n 1).

${ }^{67}$ For an engaging discussion on this topic see, Paul Roberts (n 18) and David Ormerod (n 18).
} 


\section{The 'social disutility' model}

This article posits that the courts often favour a paternalistic (or moralistic) approach when determining the effectiveness of consent to bodily harm in English criminal law. Given the importance of personal autonomy, it is submitted that the social utility model that has been applied to bodily modifications is not the best approach to take. The social utility model states that once the critical level of harm has been reached, it is necessary for the defence to demonstrate that the particular activity is in the public interest and should be permitted. Indeed, this was the test that was used by the majority in $R v$ Brown. ${ }^{68}$ There are significant problems when phrasing the test in this way. The 'public interest' criterion has not been properly articulated by Parliament, the judiciary, or academics. Whilst some of the exceptions listed by Lord Slynn ${ }^{69}$ clearly serve a valuable societal purpose, e.g. surgery, others are less clear. For example, it is not apparent what societal purpose activities such as tattooing, ear-piercing, male circumcision, and boxing serve. Some guidance on this matter can be extrapolated from the case of $R v$ Jobidon, ${ }^{70}$ in which the Supreme Court of Canada briefly considered the public interest criterion. Whilst adopting the social utility model with respect to the provisions of the Canadian Criminal Code, the judiciary held that social utility means conduct that is 'for the good of the people involved, and often for a wider group of people as well'. ${ }^{71}$ Whilst such commentary is welcome, this offers little to articulate the circumstances in which consent to bodily harm is lawful. Since judicial articulation on permissible forms of consent to harmful conduct is rare, the Court of Appeal's decision on bodily modifications in $R v B M^{72}$ is of both legal and theoretical importance.

\footnotetext{
${ }^{68}$ (n 1) (Lord Templeman).

${ }^{69} R v$ Brown (n 1).

${ }^{70}$ [1991] 2 SCR 714.

${ }^{71}$ (n 70) 767.

${ }^{72}$ (n 3).
} 
The analysis offered here is that the social utility approach is not the best model to adopt. Rather, it is submitted that, with respect to the consensual infliction of harm outside of the recognised categories, unless the prosecution is able to articulate specific reasons for prohibiting the specific conduct, consent will be effective up to the level of grievous bodily harm. ${ }^{73}$ This is the social disutility model. This approach has been considered by academics and (briefly) by the judiciary. Lord Mustill, in his dissenting judgment in $R v$ Brown, ${ }^{74}$ clearly advocated a social disutility model. His Lordship held:

As I have ventured to formulate the crucial questions, it asks whether there is good reason to impress upon s 47 an interpretation which penalises the relevant level of harm irrespective of consent: ie to recognise sado-masochistic activities as falling squarely into a special category of acts, such as duelling and prize fighting, which 'the law says shall not be done' 75

It is submitted that the social disutility model offers two attractive advantages over the social utility model. First, as noted above, it is sometimes very difficult to articulate why certain (lawful) acts should be permitted. This is particularly true of (lawful) bodily modifications such as tattooing and piercing. These procedures involve the infliction of pain for non-therapeutic purposes and can sometimes result in permanent disfigurement. However, under the social disutility model, unless reasons can be articulated as to why the public interest requires their prohibition, consent is effective, and the procedures deemed lawful. In the case of tattooing and piercing, as there is a plethora of legislation that regulates the procedures, protecting customers, and are (normally) reversible, there is no public justification for criminal

\footnotetext{
${ }^{73}$ The view presented here is based on David Kell's 'social disutility model' in David Kell, 'Social Disutility and the Law of Consent' (1994) 14 Oxford Journal of Legal Studies 121.

${ }^{74}$ (n 1) (Lord Mustill).

75 (n 1$) 273$.
} 
interference. ${ }^{76}$ Such an approach is not abhorrent in criminal law and the judiciary have sometimes framed questions of public interest and the effectiveness of consent to bodily harm in this way. For example, in $R v$ Jobidon, ${ }^{77}$ it was held that unless the public interest requires the nullification of consent, conduct would be deemed lawful. ${ }^{78}$ Therefore, this approach would not pose significant difficulty for the judiciary to implement.

Second, the model of social disutility provides greater emphasis on individual autonomy. English criminal law, in a modern democratic society, places great significance on this interest. Since consent to (serious) bodily harm will inevitably concern the interests of individual autonomy being balanced against other philosophical justifications (paternalism and legal moralism), it should be for the prosecution to demonstrate that individual autonomy needs to be interfered with for some larger societal interest. This would force the judiciary to question and re-examine the rationale for prohibiting conduct in light of changing societal norms, ensuring that autonomy is protected unless interference is absolutely necessary. The current social utility model allows all of these considerations to be evaded completely by placing the burden of proof on the defendant. Social utility favours paternalism and legal moralism unless a cogent argument for the protection of autonomy can be made, which is surely not correct. ${ }^{79}$

It is necessary to apply the social disutility model to extreme bodily modifications to determine whether a different outcome to the decision in $R v B M^{80}$ would likely have arisen. The model states that unless the prosecution is able to articulate specific reasons for prohibiting the

\footnotetext{
${ }^{76}$ In addition to this, on a practical level, it also seems more fitting that considerations of public interest are advanced by the prosecution, rather than the defendant.

${ }^{77}$ [1991] 2 SCR 714, at 748.

${ }^{78}$ This approach was similarly adopted in $R v$ Raabe (1984) 14 A Crim R 381 (Connolly J).

${ }^{79}$ David Kell (n 73) 128.

${ }^{80}$ (n 3).
} 
specific conduct, consent will be effective up to the level of grievous bodily harm. There are two issues that are of relevance with extreme bodily modifications. First, the level of harm that is inflicted on the customer; and second, whether there are sufficient reasons for prohibiting extreme bodily modifications. It is the first of these two issues that poses the most difficulty. As noted above, bodily modifications vary from simple ear-piercings to the removal of limbs. It is submitted that once the level of grievous bodily harm has been reached, consent becomes ineffective. This is due for several reasons, each of which articulating reasons for the prohibition of extreme bodily modifications necessary when applying a social disutility model. Where bodily modifications result in irreversible visible disfigurement or disability, there is justifiable interference to protect to the individuals opting to have such procedures. Similarly, given the prevalence of those opting to have cosmetic surgery that suffer from BDD, it is in the public interest to interfere with personal autonomy to ensure that individuals who wish to have such extreme bodily modifications receive proper medical treatment where necessary. More importantly since there is such an inherent risk in permitting severe bodily modifications to be carried out by non-medically trained professionals - the decision in $R v B M^{81}$ must be correct. $^{82}$

The uncertainty arises when bodily modifications fall between tattooing and ear-piercing and the extreme procedures carried out in this case. It is submitted that where (reversible) bodily modifications, up to the level of actual bodily harm, are performed on a consenting sane adult - their personal autonomy must outweigh the paternalistic or moralistic interference of the criminal law and deemed lawful. Where this boundary lies in practice is, however, more

\footnotetext{
${ }^{81}$ (n 3).

82 The inherent risks include the unpredictable nature of any possible harm; the difficulty in implementing safety mechanisms to prevent the occurrence of unintended harm; the potential for harm to escalate; and finally, the adverse effect such conduct has on the public.
} 
difficult to explicitly articulate. Given the poorly articulated existing legal principles and authority on this subject, Parliamentary reform on this subject is essential to determine which bodily modifications are permitted by the criminal law. Until this time, however, it is submitted that the social disutility model provides the best framework to balance individual autonomy against paternalism and moralism.

\section{Conclusion}

The judgment in $R v B M,{ }^{83}$ reaffirming the ratio in $R v$ Brown, ${ }^{84}$ means that the consent of an individual does not provide a defence to causing serious bodily harm in the case of bodily modification. Due to the shift in societal norms and expressions of individuality it is likely that these bodily modifications will continue. Therefore, as a result of $R v B M,^{85}$ the practice of extreme cosmetic body art is likely to be driven underground. It is dubious to suggest that in the future such practices will be categorised as being analogous to either tattooing, piercing, or surgical procedures (unless it is reasonable surgical interference when treating BDD). Similarly, if the criminal law permitted medically trained individuals to carry out such procedures in licenced premises, the cost of doing so would increase prices and availability so much that it is even more likely to be driven underground. Parliamentary debate on this subject is essential to determine when, and under what circumstances, common bodily modifications are accepted as being lawful - if at all. Until this happens, the law on consent, causing (serious) bodily harm, and expressions of body art and sexual gratification remains unsatisfactory. The patchwork of recognised exceptions that currently exists is becoming more difficult to theoretically and practically defend. Until Parliament perceives extreme bodily modifications

\footnotetext{
${ }^{83}$ (n 3).

${ }^{84}$ (n 1). With respect the OAPA, s. 18.

${ }^{85}$ (n 3).
} 
as being normatively acceptable with no legitimate reasons for prohibiting such procedures the judiciary's decision to criminalise such behaviour must be correct. 